\title{
Prognostic factors for mortality in 123 severe cases of necrotizing fasciitis in 5 hospitals in the Netherlands between 2003 and 2017
}

\author{
Sander van Stigt ${ }^{1} \mathbb{D} \cdot$ Merel Knubben $^{2} \cdot \operatorname{Tim}_{\text {Schrooten }}{ }^{1} \cdot{\text { Edward } \operatorname{Tan}^{2}}^{2}$
}

Received: 3 February 2021 / Accepted: 17 May 2021 / Published online: 27 May 2021

(c) The Author(s) 2021

\begin{abstract}
Purpose Necrotizing fasciitis (NF) is a severe soft tissue infection with a high morbidity and mortality. With early diagnosis and treatment this could be reduced. Unfortunately, the diagnosis of necrotizing fasciitis can be very difficult. In recent years many risk factors have been identified. In 2004, the Laboratory Risk Indicator for Necrotizing Fasciitis (LRINEC) score was developed. A tool that could help diagnosing NF. In this study, we search for prognostic factors for mortality in necrotizing fasciitis.

Methods All adult patients with histopathological or surgical confirmed NF needed to be admitted to the intensive care unit for at least 24 h between January 2003 and December 2017 in five hospitals from the Nijmegen teaching region were included. We excluded patients with other forms of soft tissue infections or patients with an intensive care unit (ICU) stay of $<24 \mathrm{~h}$ because we exclusively wanted to include patients with a fulminant course of necrotizing fasciitis.

Results We have included 123 cases. The overall mortality was $31.7 \%(N=39)$. The overall mean LRINEC score was $7.4 \pm 2.7$. Patients who died as the result of NF had a significantly higher median LRINEC score ( 8 vs. $7, p=0.034)$. Other parameters found to be associated with mortality are age $\geq 60$ years, cardiovascular disease in the medical history, $\geq 2$ comorbidities, and lactate level greater than $1.7 \mathrm{mmol} / \mathrm{L}$.

Conclusion LRINEC score should be calculated in all patients presenting with NF to provide an additional source for clinical outcome. A high LRINEC score could implicate a higher risk of mortality. Especially in elderly patients, with a cardiac history, more than two comorbidities or a lactate level greater than $1.7 \mathrm{mmol} / \mathrm{L}$.
\end{abstract}

Keywords Necrotizing fasciitis $\cdot$ Prognosis $\cdot$ Mortality $\cdot$ ICU $\cdot$ LRINEC

$\begin{array}{ll}\text { Abbreviations } & \\ \text { NF } & \text { Necrotizing fasciitis } \\ \text { LRINEC } & \begin{array}{l}\text { Laboratory Risk Indicator for Necrotiz- } \\ \text { ing Fasciitis }\end{array} \\ \text { ICU } & \text { Intensive care unit } \\ \text { RadboudUMC } & \text { Radboud Univeristy Medical Center } \\ & \text { Nijmegen } \\ \text { ETZ } & \text { Elisabeth Tweesteden Hospital Tilburg } \\ \text { GVH } & \text { Gelderse Vallei Hospital } \\ \text { RH } & \text { Rijnstate Hospital Arnhem } \\ \text { SH } & \text { Slingelang Hospital Doetinchem } \\ \end{array}$

Sander van Stigt

S.vanStigt@mst.nl

1 Department of Surgery, Traumasurgery, Medical Spectrum Twente, Koningsstraat 1, 7512 KZ Enschede, The Netherlands

2 Department of Surgery, Traumasurgery, Radboud University Medical Center, Nijmegen, The Netherlands
METC Medical ethical testing committee

$\mathrm{MCU}$

SSG

VAC

NSTI

CVD Medium care unit

Split skin graft

Vacuum assissted closure

Necrotizing soft tissue infections

Cardiovascular disease

\section{Background}

Necrotizing fasciitis (NF) is a rare but severe soft tissue infection. It is part of the Necrotizing Soft Tissue Infections, and it usually involves the fascia and subcutaneous tissue [1]. The incidence of NF ranges widely. In Thailand, the annual incidence is 15.5 cases per 100,000 [2]. Whereas, it ranges from 0.3 to 5 cases per 100,000 in Western countries [3-6]. This disease was first described by Hippocrates in the fifth century BC [7], but the term necrotizing fasciitis was first used by Wilson in 1952 [8]. Local symptoms of NF include 
intense pain, erythema, swelling, discolouration of the skin, bullae and subcutaneous emphysema. Systemic symptoms such as fever, nausea, vomiting and general malaise may also occur [9]. Diagnose of NF is difficult, because these symptoms are not specific to NF, but can also be identified in other diseases, like other soft tissue infections (e.g. cellulitis). Symptoms more specific for NF like bullae, necrosis of the skin and subcutaneous emphysema are not commonly seen at initial presentation. Therefore, misdiagnosis is not uncommon (41-96\%) [10].

NF could occur spontaneous, without a clear point of entry or after trauma. Anything compromising the integrity of the skin could develop into NF. Examples are surgical wounds, blunt trauma, needle puncture, burns, lacerations and insect bites. Though it's not rare to find no clear point of entry [9]. Comorbidities which are most commonly associated with NF are diabetes mellitus, smoking/alcohol abuses, liver cirrhosis, HIV infection, malignancy, corticosteroid therapy and chronic renal failure $[9,10]$.

Depending on the causative organisms, necrotizing fasciitis can be classified into four clinical forms [11]. Type 1 is classified by a synergistic mixture of at least one anaerobic species with one or more facultative anaerobic streptococci and members of the Enterobacteriaceae. Type 2 is usually mono-microbial and caused by group A $\beta$-haemolytic streptococcus. Sometimes it is caused by another species of the $\beta$-haemolytic streptococcus family or there could be a coinfection with Staphylococcus aureus. Type 3 is the effect of an infection with a gram-negative, often marine-related organism. It can be caused by ingestion of seafood or contamination of a wound by water contact. This type is rarely seen in Europe [9, 11]. Type $4 \mathrm{NF}$ is very rare and is caused by Candida spp. [11]. It affects mainly immunocompromised patients [12]. Type $1 \mathrm{NF}$ is most prevalent in patients presenting with this infection, with a relative incidence up to $70-80 \%$ [13].

The diagnosis of NF can be rather difficult but should be considered in patients presenting with rapidly spreading erythema, pain and discolouration [10]. However, the gold standard for diagnosis is operative exploration. Common intra-operative findings are a greyish coloured and swollen fascia, exudate without purulence (also described as dishwater-like fluid) and easy blunt dissection of tissue planes. This can be further supported with fascia biopsy and tissue culture [11].

Predictors of a greater mortality found by previous studies are a white blood cell count greater than $30 \times 10^{\wedge} 9 \mathrm{~L}$, creatinine level greater than $176.8 \mu \mathrm{mol} / \mathrm{L}$, heart disease, old age and female sex [14, 15].

In 2004, Wong et al. developed the Laboratory Risk Indicator for Necrotizing Fasciitis (LRINEC) score as a diagnostic tool. This score consists of six routine laboratory tests: C-reactive protein, leukocyte count, haemoglobin level, sodium level, creatinine level and glucose level. (Table 1). A score of 6 or higher was found to have a positive predictive value of $92 \%$ and a negative predictive value of $96 \%$ [16]. Previous studies have suggested that the LRINEC score could also be an indication for the risk of mortality in patients presenting with necrotizing fasciitis [17].

\section{Methods}

\section{Study design}

This study is an expansion to a study conducted in 2014, which was designed as a retrospective cohort study [1]. The aim of our study was to explore the possibility of prognostic values for mortality.

\section{Patients}

All patients diagnosed with NF between January 2003 and December 2017 in the Radboud University Medical Center Nijmegen (RadboudUMC), the Elisabeth Tweesteden Hospital Tilburg (ETZ), the Gelderse Vallei Hospital Ede (GVH), Rijnstate Hospital Arnhem (RH) and Slingeland Hospital Doetinchem (SH) were included. All these hospitals belong to the same teaching region. The data was transferred to

Table 1 The Laboratory Risk Indicator for Necrotizing Fasciitis (LRINEC score)

\begin{tabular}{ll}
\hline & Score \\
\hline C-reactive protein $(\mathrm{mg} / \mathrm{L})$ & \\
$\quad<150$ & 0 \\
$\geq 150$ & 4 \\
Leukocyte count $\left(10^{9} / \mathrm{L}\right)$ & \\
$\quad<15$ & 0 \\
$15-25$ & 1 \\
$>25$ & 2 \\
Haemoglobin $(\mathrm{mmol} / \mathrm{L})$ & \\
$>8.4$ & 0 \\
$6.8-8.4$ & 1 \\
$<6.8$ & 2 \\
Sodium $(\mathrm{mmol} / \mathrm{L})$ & \\
$\geq 135$ & 0 \\
$<135$ & 2 \\
Creatinine $(\mu \mathrm{mol} / \mathrm{L})$ & \\
$\leq 141$ & \\
$>141$ & 0 \\
Glucose $(\mathrm{mmol} / \mathrm{L})$ & 2 \\
$\leq 10$ & \\
$>10$ & 0 \\
Maximum total & 13 \\
\hline
\end{tabular}


an online data manager (the Research manager ${ }^{\mathrm{TM}}$, version 5.20.0.3).

Patients with histopathological or surgical confirmed NF needed to be admitted to the intensive care unit for at least $24 \mathrm{~h}$ were included. Patients who had other forms of soft tissue infection or an ICU stay of $<24 \mathrm{~h}$ were excluded from this study because we exclusively wanted to include patients with a fulminant course of necrotizing fasciitis. Patients were found using each hospital's specific patient data system by using diagnostic and procedure codes. A non-WMO declaration was received from the medical ethical testing committee (METC). All local feasibility committees of each of the hospitals assessed and gave approval for expansion of the existing database.

\section{Data collection}

The diagnosis of necrotizing fasciitis was confirmed by histopathologic analysis of tissue samples provided during surgery. If no tissue samples were examined the diagnosis was based on surgical findings, consisting of greyish coloured and swollen fascia, exudate without purulence (also described as dishwater-like fluid) and easy blunt dissection of tissue planes.

We classified all cases into Type 1 or Type 2 NF based on microbiological results. Type 1 was identified as being caused by different combinations of aerobic gram-negative rods of the Enterobacteriaceae group, anaerobic bacteria and streptococci other that Streptococcus pyogenes. Type $2 \mathrm{NF}$ was identified as caused by haemolytic streptococcus group A (Streptococcus pyogenes), or in rare cases by haemolytic group C, G or Staphylococcus aureus.

Using the electronic patient charts demographic data about the patients was collected, as well as vital signs (temperature, blood pressure, heart rate and oxygen saturation), clinical symptoms of the affected body part and laboratory results at presentation. Using the laboratory results, taken on admission the LRINEC score was calculated.

Duration of symptoms, operative findings, the amount and timing of surgeries, wound treatment, results of blood and wound cultures, length of stay at the intensive care unit (ICU), the medium care unit (MCU) and total duration of hospitalisation were noted. Finally, the mortality and the amount of days after which patients died were documented.

\section{Statistical analysis}

The patients were stratified into different groups to evaluate which characteristics could implicate a higher mortality. For continuous variables, it was first assessed whether there was a normality using the Shapiro-Wilk test. When there was normality, a Student $t$ test was used to compare the means of both groups. If this was not the case the Mann-Whitney $U$ test was used to compare the medians. For categorical variables the Pearson's Chi-square $\left(\chi^{2}\right)$ test was used. A 2-tailed $p<0.05$ was considered significant. IBM® SPSS $®$ statistics version 25 was used for the analysis of our data.

\section{Results}

\section{Initial assessment}

A total of 123 patients were included (32 RadboudUMC, 34 ETZ, 24 GVE, $23 \mathrm{RH}, 10 \mathrm{SH})$. Seventy-five patients were male $(61 \%)$. The median age was 59 years, with a mean of 57.5 years (range 21-85 years). The characteristics of our study population are summarised in Table 2 .

\section{LRINEC score}

The LRINEC score could be calculated on admission in 107 patients ( $87 \%) .84$ patients (79\%) had a LRINEC of $\geq 6$, and 61 patients a score $\geq 8(56 \%)$. In 11 cases the CRP was missing and in 5 cases the glucose level. The mean LRINEC score was $7.4 \pm 2.7$. A Mann-Whitney $U$ test revealed a significant difference in the LRINEC-score of deceased patients $\left(\mathrm{Q}_{1}=7.0 \mid\right.$ median $\left.=8.0 \mid \mathrm{Q}_{3}=10.0, n=31\right)$ and those who survived $\mathrm{NF}\left(\mathrm{Q}_{1}=5.25 \mid\right.$ median $\left.=7 \mid \mathrm{Q}_{3}=9.0, n=76\right)$, $p=0.035$. This means that patients who eventually died as the result of NF had a higher LRINEC score on admittance into the hospital.

\section{Mortality rates}

A Pearson Chi-square $\left(\chi^{2}\right)$ test was used to compare mortality rates in several categorical groups. A statistically different mortality rate was found in patients over the age of 60 , patients with a history of cardiovascular disease, two or more comorbidities or a lactate level of $1.7 \mathrm{mmol} / \mathrm{L}$ or higher. All results are shown in Table 3.

\section{Discussion}

Necrotizing fasciitis is a part of the necrotizing soft tissue infections (NSTI), and still has a high rate of morbidity and mortality. Our existing research/database of 58 was expanded with 85 new cases of NF, bringing the total up to 123 patients [1]. This fact strengthens our position as one of the largest European cohorts. Additional large studies about the LRINEC score have been conducted in Asia, Australia, the US and the Middle-East [16, 18]. The LRINEC score could successfully be calculated in 107 patients, resulting in a mean score of $7.37(0-13$, SD 2.7) The LRINEC score could not be calculated in 16 patients because of missing 
Table 2 Baseline characteristics

\begin{tabular}{|c|c|}
\hline Age (years) & $57.5 \pm 14.2(21-85)$ \\
\hline Gender ( $\%$ male) & 61 \\
\hline Co morbidities $(\#)^{1}$ & $2.2 \pm 1.8(0-8)$ \\
\hline Medications & $5.2 \pm 5.4(0-27)$ \\
\hline Duration of symptoms (days) & $2.8 \pm 2.8(1-20)$ \\
\hline Known cause $(\%)$ & 74 \\
\hline \multicolumn{2}{|l|}{ Affected body part (\%) } \\
\hline Extremity & $49.6(N=61)$ \\
\hline Thorax & $10.6(N=13)$ \\
\hline Abdomen & $32.5(N=40)$ \\
\hline Fournier & $19.5(N=24)$ \\
\hline Head/neck & $4.9(N=6)$ \\
\hline \multicolumn{2}{|l|}{ Symptoms at initial presentation (\%) } \\
\hline Pain & $69.1(N=85)$ \\
\hline Erythema & $82.1(N=101)$ \\
\hline Swelling & $86.2(N=106)$ \\
\hline Blisters & $20.3(N=25)$ \\
\hline Ulceration & $21.1(N=26)$ \\
\hline Crepitation & $13.0(N=16)$ \\
\hline Loss of sensibility & $2.4(N=3)$ \\
\hline Pus & $13(N=16)$ \\
\hline Other & $15.4(N=19)$ \\
\hline $\begin{array}{l}\text { Time from presentation till surgery } \\
\text { (hours) }\end{array}$ & $10.5 \pm 12.5(1.5-82.3) N=103$ \\
\hline Number of surgeries & $3.6 \pm 2.5(0-13)$ \\
\hline Mortality (\%) & $31.7(N=39)$ \\
\hline Time till death (days) & $9.3 \pm 18.2(1-77)$ \\
\hline \multicolumn{2}{|l|}{ Hospitalization, excl. Deaths $(N=84)$} \\
\hline ICU (days) & $11.8(1-142 \pm 17.8)$ \\
\hline MCU (days) & $2.0(0-24 \pm 4.5)$ \\
\hline Ward (days) & $26.0(0-84 \pm 19.1)$ \\
\hline Total (days) & $39.8(2-117 \pm 30.3)$ \\
\hline Complications (\#) & $1.1 \pm 1.4(0-6)$ \\
\hline \multicolumn{2}{|l|}{ Microorganism(s) found (\%) } \\
\hline Group A hemolytic streptococcus & $28.5(N=35)$ \\
\hline Group B hemolytic streptococcus & $0.8(N=1)$ \\
\hline Other monoculture & $26.8(N=33)$ \\
\hline Mix of microorganisms & $42.3(N=52)$ \\
\hline No positive cultures & $1.6(N=2)$ \\
\hline \multicolumn{2}{|c|}{ Wound therapy $(\%)$, excl. deaths $(N=84)$} \\
\hline Synthetic skin dressing + SSG & $2.4(N=2)$ \\
\hline SSG & $48.8(N=41)$ \\
\hline VAC & $59.5(N=50)$ \\
\hline Other & $32.1(N=27)$ \\
\hline LRINEC score & $7.4 \pm 2.7(0-13)$ \\
\hline
\end{tabular}

Continuous data is presented as mean with standard deviation and range

$I C U$ intensive care unit, $M C U$ Medium care unit, $S S G$ split skin graft, $V A C$ vacuum-assisted closure, LRINEC Laboratory Risk Indicator for Necrotizing Fasciitis

${ }^{1}$ Number of diagnosis that patient had prior to presentation with NF: obesity, diabetes, cardiovascular history, malignancy, immune compromised, renal insufficiency, alcohol abuse, chronic liver disease, drug use or other data. In 11 cases this was because of missing CRP levels, most cases dated from the early 2000's when CRP was not regularly used to monitor infection.

The value of the LRINEC score has been a point of discussion since publication by Wong et al. in 2004. Although exceptions have been published, we believe, like other larger studies, that the LRINEC score could be of value in the diagnosis and prognosis of necrotizing fasciitis [19]. When a LRINEC score of 7.5 or higher is found we suggest that the patient and relatives should be informed that this could point to a more unfavourable outcome. Especially when this is found in combination with other predictors of higher mortality. Because the LRINEC score was not normally distributed it is more challenging to find a right cut-off value. This value was chosen because of the found difference in mean scores when comparing survivors vs non-survivors. Bechar et al. concluded that the LRINEC score could be improved by including clinical symptoms such as pain, pyrexia and the presence of comorbidities. The LRINEC score is based on an Asian population that includes type 3 necrotic fasciitis caused by vibrio spp. No cases of type $3 \mathrm{NF}$ were found in this study. There is a difference in clinical manifestation between different types of NF [11]. Type 3 necrotizing fasciitis is rare in western countries. The difference between Asian and Western populations could argue in favour of a separate LRINEC score calibrated on a European/Western population.

Previous studies suggest that survival is significantly increased among patients taken to surgery within $24 \mathrm{~h}$ after admission compared to those of whom surgery was delayed for more than $24 \mathrm{~h}$ [10, 20-22]. In our study, a Chi-square test for independence indicated no significant association between time of presentation till surgery and mortality. 104 patients $(85 \%)$ included in this study were operated within $24 \mathrm{~h}$ after presentation at the hospital. More recent research even suggests that surgery within $6 \mathrm{~h}$ has an even better outcome [23]. Some additional analysis were performed using these statements, but we did not find a significant difference in mortality with the time between presentation to surgery being $6 \mathrm{~h}$. This may be explained by the quick and easy availability of an emergency department in the Netherlands. Another explanation could be the inclusion criteria of this study, mainly the minimal duration of ICU admittance being $>24 \mathrm{~h}$. This entails that only patients with a fulminant course of NF were included in the data analysis. Patients who had the biggest benefit of early intervention were excluded. This could also explain the slightly higher mortality rate in our patients in comparison to other studies [10]. Recent studies describe mortality rates between 15 and $49 \%$, with an average mortality of $29 \%$ [22, 24]. Our data show an overall mortality of $31.7 \%$.

Other studies suggested that a white blood cell count greater than $30 \times 10^{\wedge} 9 \mathrm{~L}$, creatinine level greater than 
Table 3 Mortality rates in various categories

\begin{tabular}{|c|c|c|c|}
\hline & \multicolumn{2}{|l|}{ Deceased } & \multirow[t]{2}{*}{$p$ value } \\
\hline & Yes & No & \\
\hline \multicolumn{4}{|l|}{ Torso vs. Extremities } \\
\hline Central & $35.7 \%(N=20)$ & $64.3 \%(N=36)$ & \multirow[t]{2}{*}{1.000} \\
\hline Peripheral & $34.7 \%(N=17)$ & $65.3 \%(N=32)$ & \\
\hline \multicolumn{4}{|l|}{ Type 1 vs 2} \\
\hline Type 1 & $37 \%(N=30)$ & $63 \%(N=51)$ & \multirow[t]{2}{*}{0.067} \\
\hline Type 2 & $18.4 \%(N=7)$ & $81.6 \%(N=31)$ & \\
\hline \multicolumn{4}{|c|}{ Surgery $<24 \mathrm{~h}$ vs. $>24 \mathrm{~h}$} \\
\hline$<24 \mathrm{~h}$ & $30.9 \%(N=39)$ & $69.1 \%(N=65)$ & \multirow[t]{2}{*}{0.992} \\
\hline$>24 \mathrm{~h}$ & $33.3 \%(N=9)$ & $66.7 \%(N=18)$ & \\
\hline \multicolumn{4}{|l|}{ Surgery $<6 \mathrm{~h}$ vs. $>6 \mathrm{~h}$} \\
\hline$<6 \mathrm{~h}$ & $28.3 \%(N=17)$ & $71.7 \%(N=43)$ & \multirow[t]{2}{*}{1.000} \\
\hline$>6 \mathrm{~h}$ & $27.9 \%(N=12)$ & $72.1 \%(N=31)$ & \\
\hline \multicolumn{4}{|l|}{ Age } \\
\hline$<60$ & $19.4 \%(N=12)$ & $80.6 \%(N=50)$ & \multirow[t]{2}{*}{0.006} \\
\hline$\geq 60$ & $44.3 \%(N=27)$ & $55.7 \%(N=34)$ & \\
\hline \multicolumn{4}{|l|}{ Sex } \\
\hline Male & $29.3 \%(N=22)$ & $70.7 \%(N=53)$ & \multirow[t]{2}{*}{0.611} \\
\hline Female & $35.4 \%(N=17)$ & $64.6 \%(N=31)$ & \\
\hline \multicolumn{4}{|l|}{ Diabetes } \\
\hline Yes & $36.4 \%(N=12)$ & $63.6 \%(N=21)$ & \multirow[t]{2}{*}{0.650} \\
\hline No & $30.0 \%(N=27)$ & $70.0 \%(N=63)$ & \\
\hline \multicolumn{4}{|c|}{ Cardiovascular disease } \\
\hline Yes & $42.9 \%(N=21)$ & $57.1 \%(N=28)$ & \multirow[t]{2}{*}{0.049} \\
\hline No & $24.3 \%(N=18)$ & $75.7 \%(N=56)$ & \\
\hline \multicolumn{4}{|l|}{ Comorbidities } \\
\hline$<2$ & $16.3 \%(N=8)$ & $83.7 \%(N=41)$ & \multirow[t]{2}{*}{0.005} \\
\hline$\geq 2$ & $41.9 \%(N=31)$ & $58.1 \%(N=43)$ & \\
\hline \multicolumn{4}{|l|}{ Leucocytes } \\
\hline$<30$ & $29.6 \%(N=34)$ & $70.4 \%(N=81)$ & \multirow[t]{2}{*}{0.123} \\
\hline$\geq 30$ & $62.5 \%(N=5)$ & $37.5 \%(N=3)$ & \\
\hline \multicolumn{4}{|l|}{ Creatinine } \\
\hline$<176.8$ & $28.4 \%(N=21)$ & $71.6 \%(N=53)$ & \multirow[t]{2}{*}{0.437} \\
\hline$\geq 176.8$ & $36.7 \%(N=18)$ & $63.3 \%(N=31)$ & \\
\hline \multicolumn{4}{|l|}{ Lactate } \\
\hline$<1.7$ & $8.7 \%$ & $91.3 \%$ & 0.036 \\
\hline$\geq 1.7$ & $(N=2) 33.7 \%(N=8)$ & $(N=21) 66.3 \%(N=55)$ & \\
\hline CRP & & & \\
\hline$<150$ & $29.4 \%(N=5)$ & $70.6 \%(N=12)$ & 1.000 \\
\hline$>150$ & $29.2 \%(N=28)$ & $70.8 \%(N=68)$ & \\
\hline Type 1 NF & & & \\
\hline Mono culture & $42.9 \%(N=15)$ & $57.1 \%(N=20)$ & 0.461 \\
\hline Mix of organisms & $32.7 \%(N=17)$ & $67.3 \%(N=35)$ & \\
\hline
\end{tabular}

$176.8 \mu \mathrm{mol} / \mathrm{L}$, and heart disease at hospital admission were predictors of a higher mortality [15]. Our data only partly supports these claims. Our study only supported the previous data found that a history or cardiovascular disease (CVD) was associated with a higher mortality rate. $(42.9 \%$ vs. $24.3 \%, p=0.005)$. Other studies also found that an increased lactate level was associated with a higher mortality. Our data supported these findings. A cut-off point of $1.7 \mathrm{mmol} / \mathrm{L}$ was chosen based on daily practise $(33.7 \%$ vs $8.7 \%, p=0.036)$ [25, 26]. However, our data did not implicate a higher mortality in patients with a white blood cell count greater than 
$30.000 \times 10^{\wedge} 3 \mu \mathrm{L}$ (mortality $62.5 \%$ vs. $29.6 \%, p=0.123$ ) or a creatinine level greater than $176.8 \mu \mathrm{mol} / \mathrm{L}$ (36.7\% vs. $28.4 \%, p=0.437$ ).

This could be explained by the small amount of patients (groups of 3 and 5 patients) with a white blood cell count greater than $30.000 \times 10^{\wedge} 3 \mu \mathrm{L}$.

An increased age is also associated with a poor outcome in patients presenting with NF. With a cut-off of an age over 60 or 65 years in past studies $[6,15]$. Our data supported both these findings, with a mortality of $44.3 \%$ in patients $\geq 60$ years vs. $19.4 \%<60$ years $(p=0.006)$ and a mortality of $47.6 \%$ in patients $\geq 65$ years vs. $23.5 \%<65$ years $(p=0.012)$.

Misiakos et al. suggested that there was a greater risk of mortality in females [15]. However, like the study conducted by Benjelloun et al., our data did not support these claims [27]. In females, there was a mortality rate of $35.4 \%$ vs. $29.3 \%$ in males. This was not a significant difference with a $p$ value of 0.611 .

A research conducted by Leiblein et al. showed high amputation rates in patients with diabetes mellitus (DM). No significance was found for LRINEC score and age [28]. Goh et al. also described DM as a predictor for higher amputation rates [10]. Using Chi-squared and Mann-Whitney $U$ we did an additional analysis to find predictors for amputation. We found higher amputation rates in patients who were immunocompromised $(p=0.018)$ and patients with cardiovascular comorbidities $(p=0$ 044). LRINEC score at presentation was significantly higher in patients who later underwent a amputation. Age was not found as a predictor for higher amputation rates. None of the comorbidities was a predictor for the duration of admission.

As previously mentioned, this is to our knowledge one of the largest databases of patients with necrotizing fasciitis in the Netherlands and Western Europe. Other studies conducted in Europe consist of 15-50 cases [6, 29, 30]. This helped us to determine whether results that were found in studies conducted in Asia, Australia and the Middle East were supported by our data.

There are some limitations to our study. Unfortunately, our research was designed as a retrospective cohort study. Regrettably, because of the long period of data collection, there were some missing data. This was both because of missing lab results, as well as incomplete patient files. As mentioned earlier, this study only included patients with NF that were admitted to an ICU for longer than $24 \mathrm{~h}$. Other forms of soft tissue infections were excluded. Therefore, the study population includes patients with an more fulminant course of NF when compared to other studies. This could have implications on mortality, LRINEC score, lab results and other outcomes.

\section{Conclusion}

Clinical presentation of NF is often with non-specific symptoms such as pain, erythema and swelling. More specific symptoms often develop in hours in the course of NF. Knowing mortality is directly related with time from presentation till surgery, we recommend that the LRINEC score should be calculated in all patients who are presented with the suspicion of NF. Providing an extra tool for diagnosis. Based on our research, if there is a score over 7.5 we recommend to prepare and inform the relatives that this could be an indication of an unfavourable outcome. Especially in elderly patients, with a cardiovascular history, two or more comorbidities or a lactate greater than $1.7 \mathrm{mmol} / \mathrm{L}$.

We would also recommend a prospective approach in further research. Because of the rarity of this disease, maybe even a nationwide approach. This could then be used to validate the LRINEC score as a diagnostic and even prognostic tool in patients presenting with a presumed necrotizing fasciitis. A international European study could be the basis of a new calibration of the LRINEC-score based on a western population consisting of mostly type 1 and $2 \mathrm{NF}$.

Acknowledgements We want to thank our colleagues from the five participating hospitals for their local support helping with the inclusion of patients: M.S. Lemson (Slingelang Hospital Doetinchem), A.M. Bosch (Gelderse Vallei Hospital), E.J. Hekma (Rijnstate Hospital Arnhem) and K.W.W. Lansink (Elisabeth Tweesteden Hospital Tilburg)

Author contributions SvS set up the research together with MK. MK collected and analysed data. TS also analysed data. MK and TS wrote the article under the supervision of SvS. ET supervised the whole process from start to finish.

Funding No funding was received for conducting this study.

Data availability The dataset used and/or analysed are available from the corresponding author on reasonable request.

\section{Declarations}

Conflict of interest The authors have no conflicts of interest to declare that are relevant to the content of this article.

Ethical approval and consent to participate A non-WMO declaration was received from the medical ethical testing committee (METC). All local feasibility committees of each of the hospitals assessed and gave approval for expansion of the existing database.

Open Access This article is licensed under a Creative Commons Attribution 4.0 International License, which permits use, sharing, adaptation, distribution and reproduction in any medium or format, as long as you give appropriate credit to the original author(s) and the source, provide a link to the Creative Commons licence, and indicate if changes were made. The images or other third party material in this article are included in the article's Creative Commons licence, unless indicated otherwise in a credit line to the material. If material is not included in 
the article's Creative Commons licence and your intended use is not permitted by statutory regulation or exceeds the permitted use, you will need to obtain permission directly from the copyright holder. To view a copy of this licence, visit http://creativecommons.org/licenses/by/4.0/.

\section{References}

1. van Stigt SF, de Vries J, Bijker JB, Mollen RM, Hekma EJ, Lemson SM, et al. Review of 58 patients with necrotizing fasciitis in the Netherlands. World J Emerg Surg. 2016;11:21.

2. Khamnuan P, Chongruksut W, Jearwattanakanok K, Patumanond J, Tantraworasin A. Necrotizing fasciitis: epidemiology and clinical predictors for amputation. Int J Gen Med. 2015;8:195-202.

3. Ellis Simonsen SM, van Orman ER, Hatch BE, Jones SS, Gren LH, Hegmann KT, et al. Cellulitis incidence in a defined population. Epidemiol Infect. 2006;134(2):293-9.

4. Naseer U, Steinbakk M, Blystad H, Caugant DA. Epidemiology of invasive group A streptococcal infections in Norway 2010-2014: a retrospective cohort study. Eur J Clin Microbiol Infect Dis. 2016;35(10):1639-48.

5. Glass GE, Sheil F, Ruston JC, Butler PE. Necrotising soft tissue infection in a UK metropolitan population. Ann R Coll Surg Engl. 2015;97(1):46-51.

6. Bocking N, Matsumoto CL, Loewen K, Teatero S, Marchand-Austin A, Gordon J, et al. High incidence of invasive group A streptococcal infections in remote indigenous communities in Northwestern Ontario, Canada. Open Forum Infect Dis. 2017;4(1):243.

7. Descamps V, Aitken J, Lee MG. Hippocrates on necrotising fasciitis. Lancet. 1994;344(8921):556.

8. Wilson B. Necrotizing fasciitis. Am Surg. 1952;18(4):416-31.

9. Angoules AG, Kontakis G, Drakoulakis E, Vrentzos G, Granick MS, Giannoudis PV. Necrotising fasciitis of upper and lower limb: a systematic review. Injury. 2007;38(Suppl 5):S19-26.

10. Goh T, Goh LG, Ang CH, Wong CH. Early diagnosis of necrotizing fasciitis. Br J Surg. 2014;101(1):e119-25.

11. Morgan MS. Diagnosis and management of necrotising fasciitis: a multiparametric approach. J Hosp Infect. 2010;75(4):249-57.

12. Cook DA, Heiner JP, Rao VK. Necrotizing candidal fasciitis following hip surgery. Orthopedics. 1990;13(7):768-70.

13. Wong CH, Chang HC, Pasupathy S, Khin LW, Tan JL, Low CO. Necrotizing fasciitis: clinical presentation, microbiology, and determinants of mortality. J Bone Jt Surg Am. 2003;85(8):1454-60.

14. Anaya DA, McMahon K, Nathens AB, Sullivan SR, Foy H, Bulger E. Predictors of mortality and limb loss in necrotizing soft tissue infections. Arch Surg. 2005;140(2):151-7 (discussion 8).

15. Misiakos EP, Bagias G, Papadopoulos I, Danias N, Patapis P, Machairas N, et al. Early diagnosis and surgical treatment for necrotizing fasciitis: a multicenter study. Front Surg. 2017;4:5.

16. Wong CH, Khin LW, Heng KS, Tan KC, Low CO. The LRINEC (Laboratory Risk Indicator for Necrotizing Fasciitis) score: a tool for distinguishing necrotizing fasciitis from other soft tissue infections. Crit Care Med. 2004;32(7):1535-41.

17. El-Menyar A, Asim M, Mudali IN, Mekkodathil A, Latifi R, AlThani $\mathrm{H}$. The laboratory risk indicator for necrotizing fasciitis (LRINEC) scoring: the diagnostic and potential prognostic role. Scand J Trauma Resusc Emerg Med. 2017;25(1):28.

18. Burner E, Henderson SO, Burke G, Nakashioya J, Hoffman JR. Inadequate sensitivity of laboratory risk indicator to rule out necrotizing fasciitis in the emergency department. West J Emerg Med. 2016;17(3):333-6.

19. Bechar J, Sepehripour S, Hardwicke J, Filobbos G. Laboratory Risk Indicator for Necrotising Fasciitis (LRINEC) Score for the assessment of early necrotising fasciitis: a systematic review of the literature. Ann R Coll Surg Engl. 2017;99(5):341-6.

20. McHenry CR, Piotrowski JJ, Petrinic D, Malangoni MA. Determinants of mortality for necrotizing soft-tissue infections. Ann Surg. 1995;221(5):558-63 (discussion 63-5).

21. Freischlag JA, Ajalat G, Busuttil RW. Treatment of necrotizing soft tissue infections. The need for a new approach. Am J Surg. 1985;149(6):751-5.

22. Stevens DL, Bryant AE. Necrotizing soft-tissue infections. N Engl J Med. 2017;377(23):2253-65.

23. Hadeed GJ, Smith J, O'Keeffe T, Kulvatunyou N, Wynne JL, Joseph B, et al. Early surgical intervention and its impact on patients presenting with necrotizing soft tissue infections: a single academic center experience. J Emerg Trauma Shock. 2016;9(1):22-7.

24. Kuckelhaus M, Hirsch T, Lehnhardt M, Daigeler A. Necrotizing fasciitis of the upper and lower extremities. Chirurg. 2017;88(4):353-66.

25. Murphy G, Markeson D, Choa R, Armstrong A. Raised serum lactate: a marker of necrotizing fasciitis? J Plast Reconstr Aesthet Surg. 2013;66(12):1712-6.

26. Chang C, Fann W, Wu S, Lin C, Hsiao C. Lactate on emergency department arrival as a predictor of in-hospital mortality in necrotizing fasciitis: a retrospective study. J Orthop Surg Res. 2019;14:73.

27. el Benjelloun B, Souiki T, Yakla N, Ousadden A, Mazaz K, Louchi A, et al. Fournier's gangrene: our experience with 50 patients and analysis of factors affecting mortality. World J Emerg Surg. 2013;8(1):13.

28. Leiblein M, Marzi I, Sander AL, Barker JH, Ebert F, Frank J. Necrotizing fasciitis: treatment concepts and clinical results. Eur J Trauma Emerg Surg. 2018;44(2):279-90.

29. Swain RA, Hatcher JC, Azadian BS, Soni N, De Souza B. A fiveyear review of necrotising fasciitis in a tertiary referral unit. Ann R Coll Surg Engl. 2013;95(1):57-60.

30. Corbin V, Vidal M, Beytout J, Laurichesse H, D'Incan M, Souteyrand $\mathrm{P}$, et al. Prognostic value of the LRINEC score (Laboratory Risk Indicator for Necrotizing Fasciitis) in soft tissue infections: a prospective study at Clermont-Ferrand University hospital. Ann Dermatol Venereol. 2010;137(1):5-11. 